\title{
Smokers with emphysema and small airway disease on computed tomography have lower bone density
}

This article was published in the following Dove Press journal:

International Journal of COPD

8 June 2016

Number of times this article has been viewed

\author{
Esther Pompe' \\ Pim A de Jong ${ }^{2}$ \\ Eva $M$ van Rikxoort ${ }^{3}$ \\ Leticia Gallardo Estrella ${ }^{3}$ \\ Werner U de Jong ${ }^{2}$ \\ Rozemarijn Vliegenthart ${ }^{4,5}$ \\ Matthijs Oudkerk ${ }^{5}$ \\ Carlijn M van der Aalst ${ }^{6}$ \\ Bram van Ginneken ${ }^{3}$ \\ Jan-Willem J Lammers' \\ Firdaus AA Mohamed \\ Hoesein ${ }^{2}$ \\ 'Department of Pulmonology, \\ ${ }^{2}$ Department of Radiology, University \\ Medical Center Utrecht, Utrecht, \\ ${ }^{3}$ Department of Radiology, Radboud \\ University Medical Center, Nijmegen, \\ ${ }^{4}$ Center for Medical Imaging-North \\ East Netherlands, University of \\ Groningen, University Medical \\ Center Groningen, Groningen, \\ the Netherlands; ${ }^{5}$ Department of \\ Radiology, University of Groningen, \\ University Medical Center Groningen, \\ Groningen, ${ }^{6}$ Department of Public \\ Health, Erasmus Medical Center, \\ Rotterdam, the Netherlands
}

Correspondence: Esther Pompe

Department of Pulmonology, University

Medical Center Utrecht, Postbus 85500

3508 GA Utrecht, Postbox: E.03.5I I,

the Netherlands

Tel +3I 30887550846

Email e.pompe@umcutrecht.nl
Abstract: Osteoporosis is more common in patients with COPD and in smokers. The aim of this study was to assess whether measures of emphysema and airway disease on computed tomography (CT) were associated with lower bone density or vertebral fractures in smokers with and without COPD. For this purpose, we included participants from the NELSON lung cancer screening trial. Bone density was measured as Hounsfield Units in the first lumbar vertebra, and vertebral fractures were assessed semiquantitatively. The 15th percentile method (Perc15) was used to assess emphysema, and the airway lumen perimeter (Pi10) was used for airway wall thickness. Expiratory/inspiratory-ratio ${ }_{\text {mean lung density }}\left(\mathrm{E} / \mathrm{I}^{-r_{a}} \mathrm{tio}_{\mathrm{MLD}}\right)$ was used as a measure for air trapping and tracheal index to assess tracheal deformity. Linear regression models and logistic regression models were used to assess associations between CT biomarkers, bone density, and presence of fractures. Exactly 1,093 male participants were eligible for analysis. Lower Perc15 and higher E/I-ratio ${ }_{\text {MLD }}$ were significantly associated with lower bone density $(b=-1.27, P=0.02$ and $b=-0.37$, $P=0.02$, respectively). Pi10 and tracheal index were not associated with bone density changes. CT-derived biomarkers were not associated with fracture prevalence. Bone density is lower with increasing extent of emphysema and small airway disease but is not associated with large airway disease and tracheal deformity. This may indicate the necessity to measure bone density early in smokers with emphysema and air trapping to prevent vertebral fractures.

Keywords: phenotyping, computed tomography, air trapping, emphysema, COPD, bone density

\section{Introduction}

Systemic consequences of COPD, such as cachexia, skeletal muscle wasting, and anemia, significantly contribute to the burden of disease. ${ }^{1,2}$ The high prevalence of osteoporosis in COPD patients is especially problematic because fractures can lead to substantial disability. ${ }^{3-5}$

Although the exact pathophysiological relationship between osteoporosis and COPD remains largely unknown, studies have shown similarities between emphysema and osteoporosis in loss of extracellular matrix and associations with inflammatory mediators such as tumor necrosis factor- $\alpha .{ }^{6,7}$ Also, Ohara et al ${ }^{8}$ showed that a relationship exists between emphysema and low bone mineral density (BMD) on dual X-ray absorptiometry. However, less is known on the relationship between bone density and airway disease. Computed tomography (CT) is increasingly used to identify biomarkers to classify COPD patients, and it could be helpful in studying the association between morphologic abnormalities underlying COPD and osteoporosis. ${ }^{9}$ Next to smoking-related lung changes on $\mathrm{CT}$, bone density measurements based on Hounsfield 
unit (HU) could provide a measure for osteoporosis and are increasingly being investigated as a diagnostic aid. ${ }^{10,11} \mathrm{~A}$ recent study showed that bone density measured with $\mathrm{CT}$ could be used to identify patients with osteoporosis. ${ }^{12}$

We hypothesized that lower bone density and vertebral fractures could be found more often in COPD patients with an emphysema-dominant phenotype, compared to COPD patients in whom chronic bronchitis is more evident. This is in line with the hypothesis of an overall wasting COPD phenotype, although these pulmonary and skeletal changes might already be present before COPD is diagnosed..$^{13}$ Therefore, the purpose of this study was to assess the association of bone density (as a proxy for osteoporosis) and vertebral fractures with several CT quantification measures for lung abnormalities in smokers with and without COPD.

\section{Methods}

\section{Participants}

The included participants were part of the Dutch and Belgium Lung Cancer Screening Trial (NELSON trial). ${ }^{14}$ After gaining information on smoking history, which was derived from questionnaires sent to the general population aged between 50 years and 75 years, participants were invited to participate in the study. ${ }^{15}$ The NELSON trial included current and former smokers aged between 50 years and 75 years, with a smoking history of at least 16.5 pack-years. Former smokers should not have quit more than 10 years prior to inclusion. Participants were excluded based on self-reported poor health status or if they were unable to climb two flights of stairs, had a recent chest CT scan, had a history of cancer, or a body weight of more than $140 \mathrm{~kg}$. The Ministry of Health of the Netherlands and the institutional ethical review board approved the NELSON trial. The NELSON trial is registered at www.trialregister.nl with trial number ISRCTN63545820 (Institutional Review Board approval number 03/040). Written informed consent was obtained from all participants. A random subset of participants selected from the University Medical Center Utrecht underwent additional lung function tests and expiratory CT and were included in the present study. ${ }^{16}$ Because of logistical reasons, not all participants underwent lung function testing.

\section{CT acquisition}

All participants underwent a low-dose paired inspiratory and expiratory volumetric CT scan, which was acquired with $16 \times 0.75 \mathrm{~mm}$ collimation (Brilliance 16P; Philips Healthcare, Best, the Netherlands). Scans were made without intravenous contrast injection. For the inspiratory CT, participants weighing $80 \mathrm{~kg}$ or less were scanned with $120 \mathrm{kVp}$ at $30 \mathrm{~mA}$, and participants weighing $>80 \mathrm{~kg}$ were scanned with $140 \mathrm{kVp}$ at $30 \mathrm{~mA}$ (estimated effective dose of $1.40 \mathrm{mSv}$ ). For the expiratory CT, participants were scanned at $90 \mathrm{kVp}$ $(\leq 80 \mathrm{~kg}$ ) or $120 \mathrm{kVp}(>80 \mathrm{~kg})$ at $20 \mathrm{~mA}$ (estimated effective dose of $0.65 \mathrm{mSv}$ ). Axial images with a slice thickness of $1.0 \mathrm{~mm}$ were reconstructed at $0.7 \mathrm{~mm}$ increment using a smooth reconstruction filter (B-filter; Philips Healthcare).

\section{CT assessment of emphysema, airway wall thickness, air trapping, and tracheal index}

The quantification of emphysema and airway wall thickness has been reported before. ${ }^{17,18}$ All quantifications were performed with CIRRUS Lung 12.03 (Cirrus, Diagnostic Image Analysis Group, Radboud University Medical Center, Nijmegen, the Netherlands; Fraunhofer MEVIS, Bremen, Germany). The lungs were segmented, and large airways were excluded. Severity of emphysema was assessed with the 15th percentile (Perc15) technique. This technique acquires the HU point below which $15 \%$ of the voxels are distributed. ${ }^{19}$ The closer the Perc 15 is to $-1,000 \mathrm{HU}$, the more emphysema is present.

For analysis of large airway disease, the airway lumen was automatically segmented as previously described. ${ }^{20}$ Airway wall thickness was calculated by the square root of wall area for a theoretical airway with an internal perimeter of $10 \mathrm{~mm}$ (Pi10). Airway wall borders were visually inspected to verify correct segmentation. ${ }^{21}$

CT air trapping was defined as the expiratory to inspiratory ratio of mean lung density (expiratory/inspiratoryratio $_{\text {mean lung density }}\left[\mathrm{E} / \mathrm{I}_{-}\right.$ratio $\left.\left._{\mathrm{MLD}}\right]\right)$ and was used as a measure of small airway dysfunction. ${ }^{22}$ Tracheal index (TI) was measured on inspiratory scans at every slice from $2.5 \mathrm{~cm}$ above the bifurcation of the main bronchi to the top of the trachea. ${ }^{23,24}$ TI was defined by the ratio of coronal and sagittal length of the trachea on the axial plane. Figures 1 and 2 illustrate all CT-derived measurements.

\section{Bone density and fracture assessment}

Bone density measurements and fracture assessment have been reported before. ${ }^{25}$ Bone density measurements were performed in the first lumbar vertebra (L1). If L1 was fractured or not visualized, bone density was measured in a visible adjacent normal vertebra. A region of interest was placed in axial view in the upper part of the vertebra between the endplate and the entrance of the vessels at the anterior midportion, in a homogeneous area of trabecular bone 

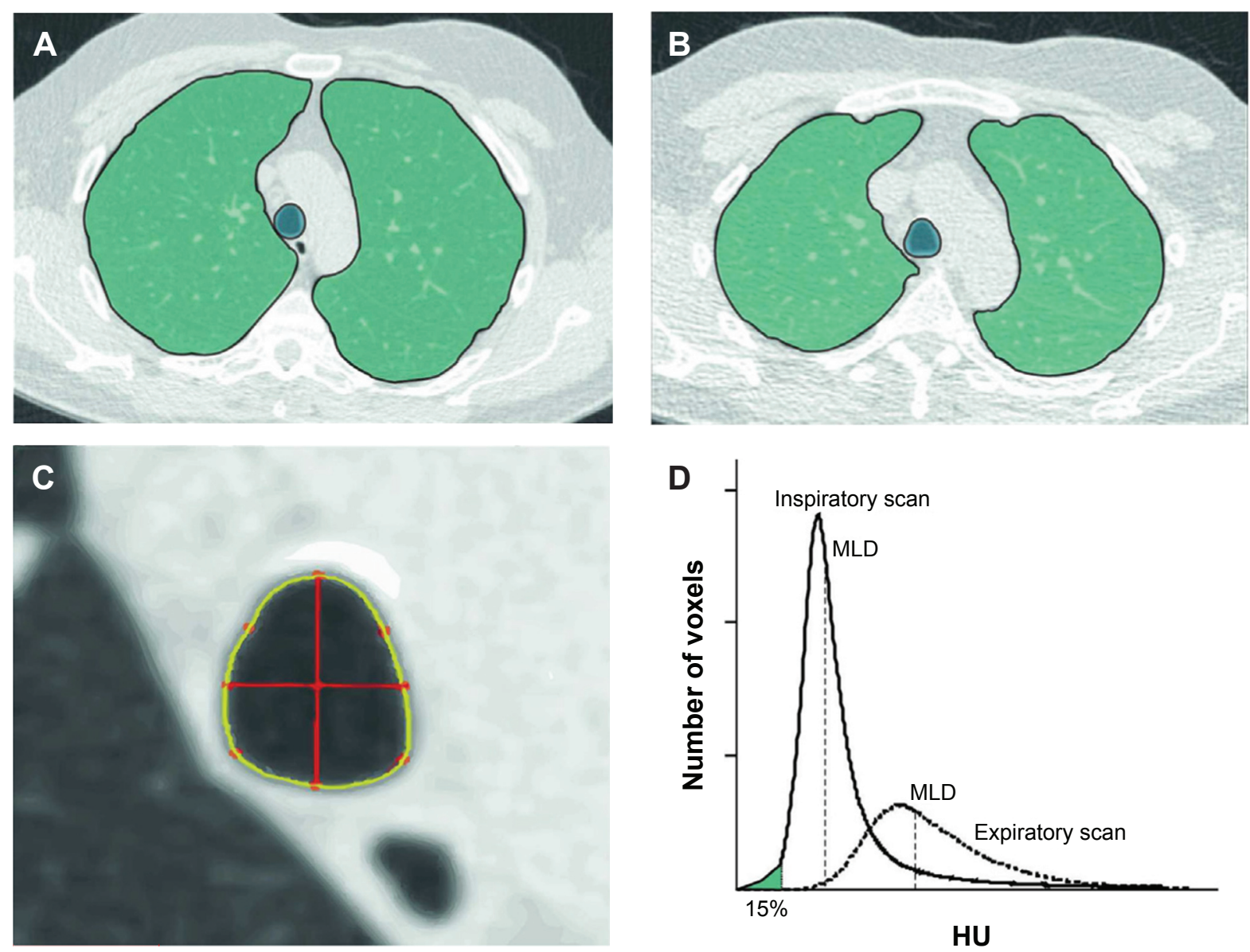

Figure I Illustration of the lung segmentation process and calculation of emphysema, air trapping, and TI.

Notes: (A) Axial inspiratory CT image. (B) Axial expiratory CT image. Both (A and B) show lung segmentation (outlined green area) of the right and left lung on an axial slice. The trachea was segmented as well. (C) Magnified image of the trachea as shown in (A). TI is computed as follows. First, the centroid of the trachea is computed. Then, two orthogonal axes $\left(0^{\circ}\right.$ and $\left.90^{\circ}\right)$ are drawn that cross the centroid (red lines). Tl is computed as the ratio of the coronal and sagittal lines. (D) Graph showing attenuation histograms for the inspiratory and expiratory CT. The 15th percentile (measure for emphysema) is calculated as the HU point below which $15 \%$ of the voxels are distributed. Air trapping is calculated as the ratio of MLD on the expiratory and inspiratory images.

Abbreviations: CT, computed tomography; HU, Hounsfield Unit; MLD, mean lung density; TI, tracheal index.

(Figure 3). Regions of interest were as large as possible, and focal heterogeneous areas were avoided. All measurements were taken by a research student (WJ) under the supervision of a chest radiologist (PJ). Vertebral fracture assessment was conducted in a sagittal plane. Height loss of $>20 \%$ was considered a vertebral facture, compared to an adjacent, nonfractured vertebra. Fracture assessment was executed using semiquantitative method of Genant et al. ${ }^{26}$

\section{Pulmonary function testing}

All participants underwent prebronchodilator pulmonary function tests according to the European Respiratory Society/ American Thoracic Society guidelines with ZAN equipment (ZAN Messgeräte GmbH, Oberthulba, Germany). ${ }^{27}$ Forced expiratory volume in 1 second $\left(\mathrm{FEV}_{1}\right)$ and forced vital capacity were measured. COPD was defined according to the Global Strategy for the Diagnosis, Management, and
Prevention of COPD (Global Initiative for Chronic Obstructive Lung Disease). ${ }^{1}$

\section{Statistical analysis}

Mean and standard deviation (SD) values were calculated for normally distributed data and median and interquartile range for non-normally distributed data. Univariate analyses were used to assess the association of bone density with CT-related COPD measures (Perc15, Pi10, E/I-ratio ${ }_{\text {MLD }}$, and TI) and demographic characteristics (age, body mass index $[\mathrm{BMI}]$, smoking status, pack-years, $\mathrm{FEV}_{1} \%$ predicted, and COPD status [absent/present]). Biomarkers with a $P$-value of $<0.20$ were included in a multivariate linear regression model.

To compare Pi10, Perc15, E/I-ratio ${ }_{\mathrm{MLD}}$, and TI between participants with and without a fracture, a Student's $t$-test was performed. Logistic regression was used to study the association 
A
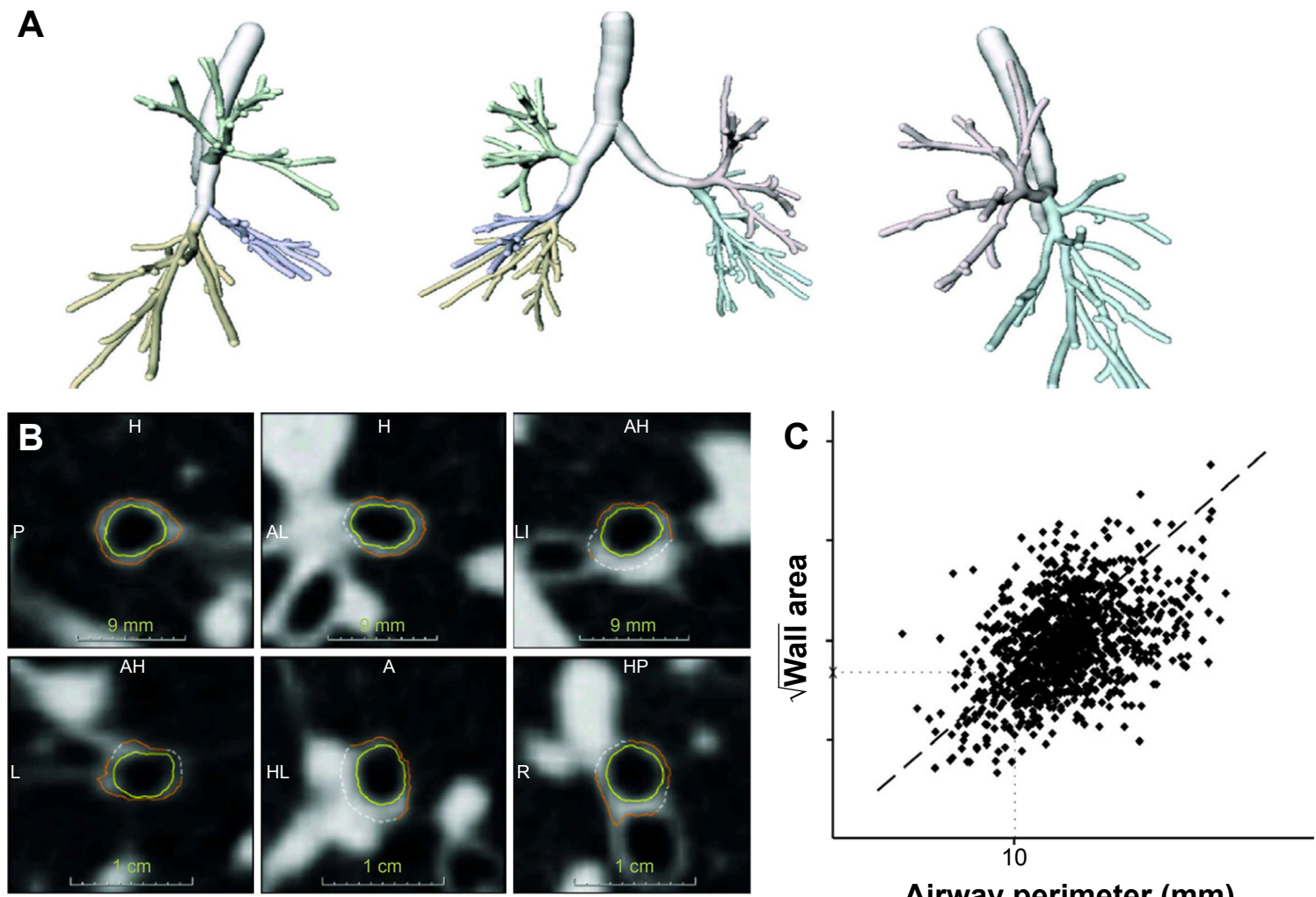

Airway perimeter $(\mathrm{mm})$

Figure 2 Illustration of the bronchial segmentation process and the calculation of bronchial wall thickness.

Notes: (A) Bronchial tree segmentation of the right and left lung, separately and combined. (B) Random selection of bronchial cross sections, showing an inner and an outer wall boundary (yellow and orange lines). From these boundaries, the wall area is calculated. (C) Line graph in which the square root of the wall area is plotted against the internal perimeter. A regression line (dashed line) is drawn through the measurements, from which the square root of wall area for a theoretical bronchus with $10 \mathrm{~mm}$ lumen perimeter (ie, Pi l0) was calculated (dotted lines). Adapted from Mets OM, Schmidt M, Buckens CF, et al. Diagnosis of chronic obstructive pulmonary disease in lung cancer screening Computed Tomography scans: independent contribution of emphysema, air trapping and bronchial wall thickening. Respir Res. 2013;14:59.20

Abbreviations: Pil O, airway wall thickness at an internal perimeter of $10 \mathrm{~mm}$; L, left; R, right; P, posterior; A, anterior; $\mathrm{H}$, head; I, inferior.

of vertebral fractures with Perc15, Pi10, E/I-ratio ${ }_{\mathrm{MLD}}$, and TI, while adjusting for demographic characteristics. A significance level of $P<0.05$ was considered significant. Statistical Package for the Social Sciences Version 20 was used for all statistical analyses (IBM Corporation, Armonk, NY, USA).

\section{Results}

\section{Participants}

Exactly 1,140 male participants were included with a mean (SD) age of 62.5 (5.3) years. Forty-seven participants were excluded because TI or Pi10 measurements failed, resulting
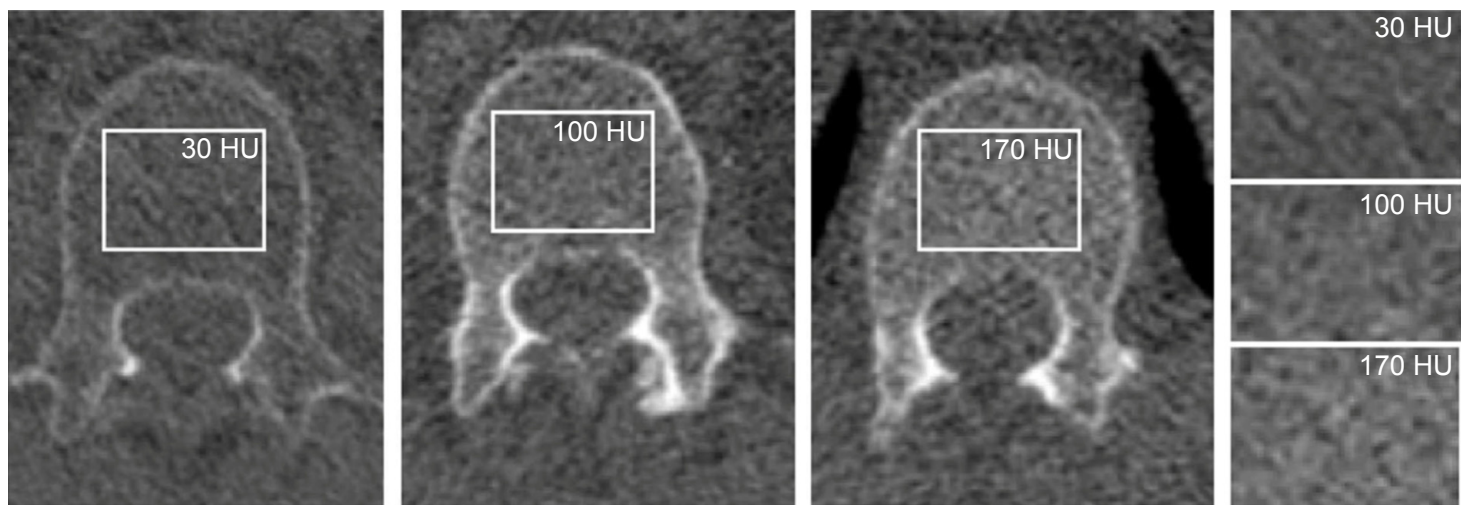

Figure 3 CT-derived bone density measurements of the spine.

Notes: Regions of interest (rectangular regions) were placed in the trabecular bone between the superior endplate and the middle of the corpus of vertebral body I (LI). The three axial images show vertebrae from different participants with different bone densities, viewed in bone window (C=300, W=I,600). The rectangular regions of interest correspond to the regions of interest placed over the vertebrae. From left to right and top to bottom, it shows gradual increase in bone density from $30 \mathrm{HU}$ to 100 and $170 \mathrm{HU}$, respectively.

Abbreviations: $\mathrm{CT}$, computed tomography; HU, Hounsfield Unit. 
Table I Participant characteristics $(\mathrm{N}=\mathrm{I}, 093)$

\begin{tabular}{ll}
\hline Characteristic & Value \\
\hline Age (years), mean \pm SD & $62.5 \pm 5.3$ \\
BMI (kg/m²), mean \pm SD & $27.1 \pm 3.6$ \\
Pack-years (years), median & $40.9(28.0-49.5)$ \\
(25th percentile-75th percentile) & \\
Current smoker, $\mathrm{n}(\%)$ & $584(53.4 \%)$ \\
FEV $(\%$ predicted), mean \pm SD & $95.1 \pm 17.5$ \\
COPD, n (\%) & $412(37.7 \%)$ \\
GOLD I, $\mathrm{n}(\%$ of COPD positive) & $264(24.2 \%)$ \\
GOLD 2, $\mathrm{n}(\%$ of COPD positive) & $125(11.4 \%)$ \\
GOLD 3, $\mathrm{n}(\%$ of COPD positive) & $23(2.1 \%)$ \\
Bone density (HU value), mean $\pm \mathrm{SD}$ & $105.9 \pm 33.3$ \\
Prevalent fracture, $\mathrm{n}(\%)$ & $95(8.7 \%)$ \\
\hline
\end{tabular}

Abbreviations: $\mathrm{BMI}$, body mass index; $\mathrm{FEV}_{1}$, forced expiratory volume in I second; GOLD, Global Initiative for Chronic Obstructive Lung Disease; HU, Hounsfield Unit; SD, standard deviation.

in 1,093 participants analyzed in the current study. Approximately one-third of the participants were classified as having COPD ( $\mathrm{n}=412 ; 37.7 \%)$, and 509 participants $(46.6 \%)$ were former smokers. Further characteristics of the participants are shown in Table 1. Mean values of Perc15, Pi10, E/I-ratio ${ }_{\mathrm{MLD}}$, and TI are shown in Table 2.

\section{Bone density and CT-related COPD measures}

The majority of bone density measurements were performed in L1 ( $\mathrm{n}=938,85.8 \%)$. Because of inhomogeneities and/or fractures in L1 or nonvisualization of L1, 140 measurements were performed in the 12th thoracic vertebra (12.8\%), 13 in the eleventh thoracic vertebra (1.2\%), and one in the second lumbar vertebra $(0.1 \%)$. Overall mean (SD) bone density was 105.9 (33.3) HU.

Univariate results are shown in Table 3. Age, pack-years, smoking status, $\mathrm{FEV}_{1} \%$ predicted, COPD status, Perc15, and $\mathrm{E} / \mathrm{I}-$ ratio $_{\mathrm{MLD}}$ were included in the multivariate model. BMI, Pi10, and TI were not associated with bone density in univariate analyses. In Table S1, the results of the first multiple linear regression model with bone density as outcome are shown. In this model, pack-years, $\mathrm{FEV}_{1} \%$ predicted, and COPD status did not associate independently with bone density. The second and final model included age, smoking status, Perc15, and E/I-ratio ${ }_{\mathrm{MLD}}$ (Table 4). With every year of aging, bone density lowers by $1.75 \mathrm{HU}$ $(P<0.001)$. Current smokers have an 8.89 HU lower bone density $(P<0.001)$. When Perc15 lowers by $10 \mathrm{HU}$, the bone density lowers by $1.27 \mathrm{HU}(P=0.02)$, and when E/I-ratio ${ }_{\text {MLD }}$ increases by $1 \%$, the bone density lowers by $0.37 \mathrm{HU}(P=0.02)$.

When comparing the effects of Perc 15 and E/I-ratio ${ }_{\text {MLD }}$ on bone density by standardization of the effect of one SD change, Perc 15 resulted in a 2.42 HU lower bone density and $\mathrm{E} / \mathrm{I}-$ ratio $_{\mathrm{MLD}}$ resulted in a $2.29 \mathrm{HU}$ lower bone density. As an example, Figure 4 includes images of a participant with normal Perc15 and normal bone density and a participant with low Perc15 and low bone density.

\section{Fracture prevalence and CT-related COPD measures}

Of 1,093 participants, 95 had a vertebral fracture (8.7\%). Participants with a fracture had a $1.4 \mathrm{HU}$ lower Perc15 $(P=0.02)$. Pi10, E/I-ratio ${ }_{\mathrm{MLD}}$, and TI were not significantly different in participants with a fracture, compared to those without ( $P=0.43, P=0.43$, and $P=0.24$, respectively) (Table 2). Table 5 shows the outcomes of the logistic regression analysis. None of the CT-related COPD measures were associated with the presence of a fracture. Only bone density $(P<0.01)$ and smoking status $(P=0.03)$ were associated with the presence of a fracture. For the complete model (Table S2).

\section{Discussion}

The purpose of this study was to assess the association between bone density and morphologic lung changes on CT in heavy smokers. Our data showed that patients with emphysema and air trapping have lower bone density. We did not find an association between airway wall thickness or trachea deformity and bone density. Also, the presence of COPD was not associated with bone density or fracture presence. Thus, low bone density is not disease-specific for COPD, but rather phenotype-specific (emphysema or small

Table 2 Mean values for CT-acquired measurements for the complete cohort and for participants with and without a fracture

\begin{tabular}{lllll}
\hline Variable & $\begin{array}{l}\text { All participants } \\
\text { (mean } \pm \text { SD) }\end{array}$ & $\begin{array}{l}\text { Participants with } \\
\text { fracture }(\mathbf{n}=\mathbf{9 5})\end{array}$ & $\begin{array}{l}\text { Participants without } \\
\text { fracture (n=998) }\end{array}$ & $\begin{array}{l}\boldsymbol{P} \text {-value } \\
\text { Pil0 }(\mathrm{mm})\end{array}$ \\
Percl5 $(\mathrm{HU})$ & $2.4 \pm 0.5$ & $2.5 \pm 0.5$ & $2.4 \pm 0.5$ & 0.43 \\
E/I-ratio $_{\text {MLD }}$ & $-907.6 \pm 19.1$ & $-908.9 \pm 22.0$ & $-907.5 \pm 18.8$ & 0.02 \\
TI & $83.7 \pm 6.2$ & $84.8 \pm 5.6$ & $83.6 \pm 6.2$ & 0.43 \\
\hline
\end{tabular}

Abbreviations: CT, computed tomography; E/I-ratio ${ }_{M L D}$, expiration to inspiration ratio of mean lung density; HU, Hounsfield Unit; Percl5, emphysema score as I5th percentile of attenuation distribution curve on inspiratory scan; Pil0, airway wall thickness at an internal perimeter of $10 \mathrm{~mm}$; SD, standard deviation; TI, tracheal index. 
Table 3 Univariate linear regression analyses for all variables with bone density as outcome

\begin{tabular}{lll}
\hline Variable & B (SE) & P-value \\
\hline Age (years) & $-1.78(0.19)$ & $<0.001$ \\
BMI $\left(\mathrm{kg} / \mathrm{m}^{2}\right)$ & $0.27(0.28)$ & 0.33 \\
Pack-years & $-0.12(0.06)$ & 0.04 \\
Smoking status & $5.79(2.01)$ & 0.004 \\
FEV $\%$ predicted & $0.15(0.06)$ & 0.008 \\
COPD status & $8.11(2.06)$ & $<0.00 \mathrm{I}$ \\
Percl5 & $0.19(0.05)$ & $<0.00 \mathrm{I}$ \\
Pil0 & $-0.19(1.97)$ & 0.92 \\
E/I-ratio & $-0.78(0.16)$ & $<0.00 \mathrm{I}$ \\
TI & $8.99(10.29)$ & 0.38 \\
\hline
\end{tabular}

Abbreviations: B, unstandardized coefficient; BMI, body mass index; E/I-ratio ${ }_{M L D}$, expiration to inspiration ratio of mean lung density; $\mathrm{FEV}_{1}$, forced expiratory volume in I second; Perc I5, emphysema score as I5th percentile of attenuation distribution curve on inspiratory scan; Pil0, airway wall thickness at an internal perimeter of $10 \mathrm{~mm}$; SE, standard error; TI, tracheal index.

airway disease), and could therefore provide relevant prognostic information in a specific group of smokers.

With CT, we are able to directly measure the presence of airway wall thickening from large and medium airways $(>2-2.5 \mathrm{~mm}$ ) by using Pi10 and indirectly measure the presence of air trapping (ie, small airway disease; airways $<2 \mathrm{~mm}$ ) by using E/I-ratio ${ }_{\mathrm{MLD}}{ }^{28}{ }^{2}$ Therefore, Pi10 and E/I-ratio ${ }_{\mathrm{MLD}}$ are thought to represent different anatomical parts of the airway tree. In this study, we showed that bone density was associated with emphysema and small airway disease, but airway wall thickening of the larger airway walls was not. The discrepancy between the association of E/I-ratio ${ }_{\mathrm{MLD}}$, Pi10, and bone density might be explained by a difference in underlying systemic processes in small and large airway disease. ${ }^{29}$

There are several studies that evaluated bone density in participants with COPD. Ohara et $\mathrm{al}^{8}$ used CT measurements to evaluate 65 COPD patients with emphysema and showed that pulmonary emphysema was associated with reduced bone density. Our study confirmed these results in a larger study population, but we also included current and former smoking participants without COPD and evaluated other smoking-related changes such as small airway disease, large airway disease, and trachea deformity, next to emphysema. In this way, the impact of COPD and different characteristics of COPD on bone density could be evaluated. Bon et $\mathrm{al}^{30}$ showed there was a strong and independent association between emphysema and low bone density as well, but they only used visual emphysema scores.

Rutten et $\mathrm{a}^{13}$ demonstrated that fat-free mass index, as a measure of muscle wasting, decreases as the level of emphysema increases in participants with COPD. This relationship was independent of airway wall thickness. Our study complemented these findings by showing an independent association between emphysema and bone density. Moreover, we

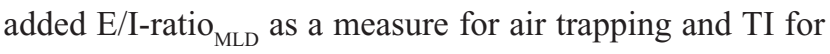
trachea deformity.

When interpreting the results of the study by Rutten et al combined with the results of our present study, there is an indication that an emphysema phenotype does not only involve destruction of alveolar walls, but also systemic processes that result in destruction of soft tissue and bone. ${ }^{31}$ While the pathophysiological relationship between tissue inflammation and destruction in the lungs and in the whole body is not confirmed yet, it is hypothesized that an inflammatory response resulting in protease antiprotease imbalance could lead to tissue destruction in both lungs and the whole body. ${ }^{32}$

A vertebral fracture in COPD patients may interfere with these patients' already compromised pulmonary function. ${ }^{5}$ Therefore, early recognition of low bone density in this patient group is of great importance in order to prevent a fracture. Several factors have been reported to contribute to reduced bone density in COPD patients, such as BMI, $\mathrm{FEV}_{1}$, smoking, inactivity, and corticosteroid therapy. ${ }^{33,34}$ Our results show that smokers with emphysema and air trapping are more at risk for lower bone density than smokers with large airway disease. With this, a specific patient group could be examined and possibly be selected for preventive care.

Our study has limitations. First, our cohort consisted of only male participants with mild emphysema. However, it has been shown that osteoporosis affects men with severe COPD to a similar degree as females, which highlights the

Table 4 Final multiple linear regression model for associated variables and their effect on bone density

\begin{tabular}{|c|c|c|c|c|}
\hline Variable & Increment or comparison & $\begin{array}{l}\text { Change in bone density } \\
\text { per unit change in variable }\end{array}$ & $95 \% \mathrm{Cl}$ & $P$-value \\
\hline Age (years) & Plus I year & -1.75 & -2.12 to -1.38 & $<0.001$ \\
\hline Smoking status & Current versus former smoker & -8.89 & -12.77 to $-5.0 \mid$ & $<0.001$ \\
\hline Percl5 & Decrease of $10 \mathrm{HU}$ & -1.27 & -2.31 to -0.02 & 0.02 \\
\hline E/I-ratio ${ }_{M L D}$ & Increase of $1 \%$ & -0.37 & -0.69 to -0.05 & 0.02 \\
\hline
\end{tabular}

Abbreviations: $\mathrm{Cl}$, confidence interval; E/I-ratio ${ }_{M L D}$, expiration to inspiration ratio of mean lung density; HU, Hounsfield Unit; Percl5, emphysema score as I5th percentile of attenuation distribution curve on inspiratory scan. 


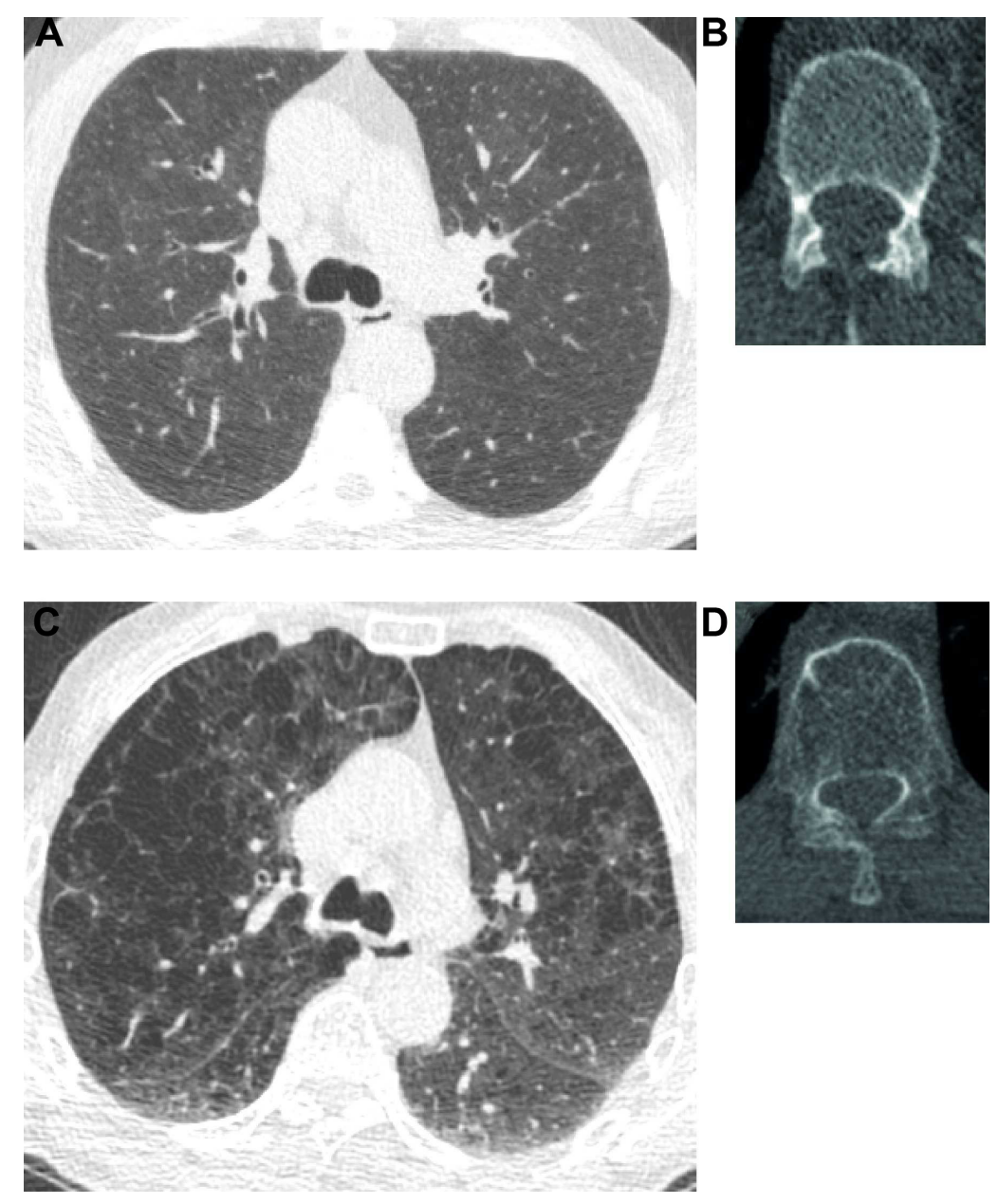

Figure 4 CT images of two participants.

Notes: Lung images are shown in lung window $(C=-600, W=I, 600)$ and vertebral images in bone window $(C=300, W=I, 600)$. $(A$ and $B)$ Show $C T$ images of a currently smoking participant of age 65 years (49.5 pack-years). He does not have COPD. The images show normal lung and bone tissue on CT. Percl5 was $-852 \mathrm{HU}$, and bone density was I50 HU. (C and D) Show CT images of a 63-year-old currently smoking participant (38 pack-years). He is diagnosed with COPD GOLD stage 2 . The lung image clearly shows signs of emphysema and Percl 5 was $-957 \mathrm{HU}$. Bone tissue was visually less dense when compared with image (B). Measured bone density was $39 \mathrm{HU}$.

Abbreviations: CT, computed tomography; GOLD, Global Initiative for Chronic Obstructive Lung Disease; HU, Hounsfield Unit; Perc I5, emphysema score as I5th percentile of attenuation distribution curve on inspiratory scan.

importance of early screening in men as well. ${ }^{35}$ Second, we did not measure fat-free mass or the use of corticosteroid drugs, while both are associated with bone density. ${ }^{36,37}$ Although fat-free mass could be a better method to evaluate soft tissue loss, BMI has been shown to be correlated with low BMD in patients with COPD. ${ }^{38}$ Because our population was considered to be relatively healthy, the impact of the use of corticosteroids could be limited. Third, unlike emphysema and airway wall thickening, there is no pathological

Table 5 Logistic regression model of significant covariates with the presence of a vertebral fracture as outcome

\begin{tabular}{llll}
\hline Variable & Odds ratio & $\mathbf{9 5 \%} \mathbf{C l}$ for odds ratio & $\boldsymbol{P}$-value \\
\hline Smoking status & 1.77 & $\mathrm{I} .13-2.78$ & $0.0 \mathrm{I}$ \\
Bone density & 0.99 & $0.98-0.99$ & $<0.00 \mathrm{I}$ \\
\hline
\end{tabular}

Abbreviation: $\mathrm{Cl}$, confidence interval. correlation study available for E/I-ratio ${ }_{M L D}$ as a measure of air trapping. However, several studies have shown that E/I-ratio ${ }_{\text {MLD }}$ is the most suitable criterion for assessing small airway disease. ${ }^{21,23,39}$ Lastly, we only included emphysema, air trapping, and airway wall thickening as CT measures of lung disease but did not include signs of interstitial lung disease, which has been shown to be associated with BMD as well. ${ }^{40,41}$

\section{Conclusion}

This study showed that bone density is significantly lower in smokers with emphysema and small airway disease on CT. It is, however, not associated with large airway wall thickening or trachea deformity. These extrapulmonary skeletal impairments in patients with emphysema and small airway disease support the thought on the existence of a 
COPD phenotype that also includes systemic characteristics. This may indicate the necessity to measure CT-derived bone density in a specific group of heavy smokers to prevent vertebral fractures.

\section{Disclosure}

Eva van Rikxoort received grants from the Netherlands Scientific Organisation during the conduct of the study and is a cofounder and shareholder of Thirona BV. Leticia Gallardo Estrella received grants from the Netherlands Scientific Organisation during the conduct of this study. Bram van Ginneken is a cofounder and shareholder of Thirona BV and received grants from MeVis Medical Systems, Toshiba, and Delft Imaging Systems outside the submitted work. Jan-Willem Lammers received grants from TiPharma and EU during the conduct of this study. The authors report no other conflicts of interest in this work.

\section{References}

1. Global Initiative for Chronic Obstructive Lung Disease. Global Strategy for the Diagnosiss, Management, and Prevention of Chronic Obstructive Pulmonary Disease [Internet]; 2015 [cited 2015 Oct 13]. Available from: http:/www.goldcopd.org/guidelines-global-strategy-for-diagnosismanagement.html

2. Agusti A, Soriano JB. COPD as a systemic disease. COPD. 2008; 5(2):133-138.

3. de Vries F, van Staa TP, Bracke MS, Cooper C, Leufkens HG, Lammers JW. Severity of obstructive airway disease and risk of osteoporotic fracture. Eur Respir J. 2005;25(5):879-884.

4. Lehouck A, Boonen S, Decramer M, Janssens W. COPD, bone metabolism, and osteoporosis. Chest. 2011;139(3):648-657.

5. Carter JD, Patel S, Sultan FL, et al. The recognition and treatment of vertebral fractures in males with chronic obstructive pulmonary disease. Respir Med. 2008;102(8):1165-1172.

6. Bon JM, Zhang Y, Duncan SR, et al. Plasma inflammatory mediators associated with bone metabolism in COPD. COPD. 2010;7(3):186-191.

7. Churg A, Dai J, Tai H, Xie C, Wright JL. Tumor necrosis factor-alpha is central to acute cigarette smoke-induced inflammation and connective tissue breakdown. Am J Respir Crit Care Med. 2002;166(6):849-854.

8. Ohara T, Hirai T, Muro S, et al. Relationship between pulmonary emphysema and osteoporosis assessed by CT in patients with COPD. Chest. 2008;134(6):1244-1249.

9. Romme EA, Murchison JT, Edwards LD, et al. CT-measured bone attenuation in patients with chronic obstructive pulmonary disease: relation to clinical features and outcomes. J Bone Miner Res. 2013; 28(6):1369-1377.

10. Link TM, Koppers BB, Licht T, Bauer J, Lu Y, Rummeny EJ. In vitro and in vivo spiral CT to determine bone mineral density: initial experience in patients at risk for osteoporosis. Radiology. 2004;231(3):805-811.

11. Papadakis AE, Karantanas AH, Papadokostakis G, Petinellis E, Damilakis J. Can abdominal multi-detector CT diagnose spinal osteoporosis? Eur Radiol. 2009;19(1):172-176.

12. Pickhardt PJ, Pooler BD, Lauder T, del Rio AM, Bruce RJ, Binkley N. Opportunistic screening for osteoporosis using abdominal computed tomography scans obtained for other indications. Ann Intern Med. 2013;158(8):588-595.

13. Rutten EP, Grydeland TB, Pillai SG, et al. Quantitative CT: associations between emphysema, airway wall thickness and body composition in COPD. Pulm Med. 2011:419328.
14. van Iersel CA, de Koning HJ, Draisma G, et al. Risk-based selection from the general population in a screening trial: selection criteria, recruitment and power for the Dutch-Belgian randomised lung cancer multi-slice CT screening trial (NELSON). Int J Cancer. 2007;120(4): 868-874.

15. Ru Zhao Y, Xie X, de Koning HJ, Mali WP, Vliegenthart R, Oudkerk M. NELSON lung cancer screening study. Cancer Imaging. 2011;11(1A): S79-S84.

16. Mets OM, Buckens CF, Zanen P, et al. Identification of chronic obstructive pulmonary disease in lung cancer screening computed tomographic scans. JAMA. 2011;306(16):1775-1781.

17. Mohamed Hoesein FAA, Schmidt M, Mets OM, et al. Discriminating dominant computed tomography phenotypes in smokers without or with mild COPD. Respir Med. 2014;108:136-143.

18. Jairam PM, de Jong PA, Mali WP, et al. Impact of cardiovascular calcifications on the detrimental effect of continued smoking on cardiovascular risk in male lung cancer screening participants. PLoS One. 2013;8(6):e66484.

19. Parr DG, Stoel BC, Stolk J, Stockley RA. Validation of computed tomographic lung densitometry for monitoring emphysema in alpha1antitrypsin deficiency. Thorax. 2006;61(6):485-490.

20. Mets OM, Schmidt M, Buckens CF, et al. Diagnosis of chronic obstructive pulmonary disease in lung cancer screening Computed Tomography scans: independent contribution of emphysema, air trapping and bronchial wall thickening. Respir Res. 2013;14:59.

21. Van Rikxoort EM, Baggerman W, van Ginneken B. Automatic segmentation of the airway tree from thoracic CT scans using a multi-threshold approach. The Second Workshop on Pulmonary Image Analysis. 2009: 341-349.

22. Mets OM, Zanen P, Lammers J-WJ, et al. Early identification of small airways disease on lung cancer screening CT: comparison of current air trapping measures. Lung. 2012;190(6):629-633.

23. Lee HJ, Seo JB, Chae EJ, et al. Tracheal morphology and collapse in COPD: correlation with CT indices and pulmonary function test. Eur J Radiol. 2011;80(3):e531-e535.

24. Boiselle PM, Michaud G, Roberts DH, et al. Dynamic expiratory tracheal collapse in COPD: correlation with clinical and physiologic parameters. Chest. 2012;142(6):1539-1544.

25. de Jong WU, de Jong PA, Vliegenthart R, et al. Association of COPD and smoking status with bone density and vertebral fractures in male lung cancer screening participants. J Bone Miner Res. 2014; 29(10):2224-2229.

26. Genant HK, Wu CY, van Kuijk C, Nevitt MC. Vertebral fracture assessment using a semiquantitative technique. J Bone Miner Res. 1993; 8(9):1137-1148.

27. Burgel PR. The role of small airways in obstructive airway diseases. Eur Respir Rev. 2011;20(119):23-33.

28. Cosio Piqueras MG, Cosio MG. Disease of the airways in chronic obstructive pulmonary disease. Eur Respir J Suppl. 2001;18:41s-49s.

29. Miller MR, Crapo R, Hankinson J, et al. General considerations for lung function testing. Eur Respir J. 2005;26(1):153-161.

30. Bon J, Fuhrman CR, Weissfeld JL, et al. Radiographic emphysema predicts low bone mineral density in a tobacco-exposed cohort. Am J Respir Crit Care Med. 2011;183(7):885-890.

31. Stanojkovic I, Kotur-Stevuljevic J, Spasic S, et al. Relationship between bone resorption, oxidative stress and inflammation in severe COPD exacerbation. Clin Biochem. 2013;46(16-17):1678-1682.

32. Kukkonen MK, Tiili E, Vehmas T, Oksa P, Piirilä P, Hirvonen A. Association of genes of protease-antiprotease balance pathway to lung function and emphysema subtypes. BMC Pulm Med. 2013;13:36.

33. Iqbal F, Michaelson J, Thaler L, Rubin J, Roman J, Nanes MS. Declining bone mass in men with chronic pulmonary disease: contribution of glucocorticoid treatment, body mass index, and gonadal function. Chest. 1999;116(6):1616-1624.

34. Kjensli A, Mowinckel P, Ryg MS, Falch JA. Low bone mineral density is related to severity of chronic obstructive pulmonary disease. Bone. 2007; 40(2):493-497. 
35. Li L, Brennan KJ, Gaughan JP, Ciccolella DE, Kuzma AM, Criner GJ African Americans and men with severe COPD have a high prevalence of osteoporosis. COPD. 2008;5(5):291-297.

36. Vrieze A, de Greef MH, Wijkstra PJ, Wýkstra PJ, Wempe JB. Low bone mineral density in COPD patients related to worse lung function, low weight and decreased fat-free mass. Osteoporos Int. 2007;18(9): 1197-1202.

37. Biskobing DM. COPD and Osteoporosis. Chest. 2014;121(2): 609-620.

38. Ogura-Tomomatsu H, Asano K, Tomomatsu K, et al. Predictors of osteoporosis and vertebral fractures in patients presenting with moderate-to-severe chronic obstructive lung disease. COPD. 2012;9(4): 332-337.
39. Bommart S, Marin G, Bourdin A, et al. Relationship between CT air trapping criteria and lung function in small airway impairment quantification. BMC Pulm Med. 2014;14:29.

40. Washko GR, Hunninghake GM, Fernandez IE, et al. Lung volumes and emphysema in smokers with interstitial lung abnormalities. $N$ Enlg J Med. 2011;364(10):897-906.

41. Ikezoe K, Handa T, Tanizawa K, et al. Bone mineral density in patients with idiopathic pulmonary fibrosis. Respir Med. 2015;109(9): 1181-1187. 


\section{Supplementary materials}

Bone density is associated with emphysema and air trapping in males with and without COPD.

Table SI First multiple linear regression model with bone density as outcome

\begin{tabular}{lll}
\hline Variable & B (SE) & $P$-value \\
\hline Age (years) & $-1.73(0.19)$ & $<0.001$ \\
Pack-years & $-0.03(0.06)$ & 0.56 \\
Smoking status & $8.67(2.01)$ & $<0.001$ \\
FEV, \% predicted & $-0.01(0.07)$ & 0.88 \\
COPD status & $2.02(2.53)$ & 0.43 \\
Percl5 & $0.11(0.06)$ & 0.05 \\
E/I-ratio & $-0.33(0.18)$ & 0.07 \\
\hline
\end{tabular}

Abbreviations: B, unstandardized coefficient; COPD, chronic obstructive pulmonary disease; E/l-ratio ${ }_{M I D}$, expiration to inspiration ratio of mean lung density; FEV , forced expiratory volume in I second; Perc I5, emphysema score as I5th percentile of attenuation distribution curve on inspiratory scan; SE, standard error.

Table S2 Logistic regression model of all covariates, with the presence of a fracture as outcome

\begin{tabular}{llll}
\hline Variable & Odds ratio & $\mathbf{9 5 \%}$ Cl for odds ratio & $P$-value \\
\hline Age $($ years $)$ & 1.00 & $0.96-1.04$ & 0.95 \\
BMI $\left(\mathrm{kg} / \mathrm{m}^{2}\right)$ & 0.94 & $0.88-1.02$ & 0.12 \\
Pack-years & 0.99 & $0.98-1.01$ & 0.39 \\
Smoking status & 1.71 & $1.06-2.78$ & 0.03 \\
Bone density & 0.99 & $0.98-0.99$ & $<0.001$ \\
FEV,$\%$ predicted & 1.01 & $1.00-1.03$ & 0.13 \\
COPD status & 1.11 & $0.63-1.96$ & 0.72 \\
Percl5 & 1.00 & $0.98-1.01$ & 0.47 \\
E/l-ratio & 1.01 & $0.97-1.06$ & 0.52 \\
PilO & 1.55 & $0.87-2.75$ & 0.14 \\
TI & 1.05 & $0.11-9.82$ & 0.97 \\
\hline
\end{tabular}

Abbreviations: $\mathrm{BMI}$, body mass index; $\mathrm{Cl}$, confidence interval; E/I-ratio ${ }_{M L D}$, expiration to inspiration ratio of mean lung density; $\mathrm{FEV}_{1}$, forced expiratory volume in I second; Perc 15 , emphysema score as 15 th percentile of attenuation distribution curve on inspiratory scan; Pil 0 , airway wall thickness at an internal perimeter of $10 \mathrm{~mm}$; $\mathrm{Tl}$, tracheal index.

\section{Publish your work in this journal}

The International Journal of COPD is an international, peer-reviewed journal of therapeutics and pharmacology focusing on concise rapid reporting of clinical studies and reviews in COPD. Special focus is given to the pathophysiological processes underlying the disease, intervention programs, patient focused education, and self management protocols.

\section{Dovepress}

This journal is indexed on PubMed Central, MedLine and CAS. The manuscript management system is completely online and includes a very quick and fair peer-review system, which is all easy to use. Visit $\mathrm{http} / / / \mathrm{www}$.dovepress.com/testimonials.php to read real quotes from published authors. 